HISPANIA. Revista Española de Historia, 2012, vol. LXXII, núm. 240, enero-abril, págs. 95-118, ISSN: 0018-2141

\title{
NEGOCIACIÓN DE NORMAS E INTERVENCIÓN ESTATAL EN LA GESTIÓN DEL REgadío: la ACEQUia Real del JÚCAR A MEdiados del SIGLO $\mathbf{X I X}^{1}$
}

\author{
SALVADOR CALATAYUd y SAMUEL GARRIDO \\ Universidad de Valencia y Universidad Jaume I
}

RESUMEN: La manera como se aplican las normas para repartir el agua entre los miembros de las comunidades de regantes ha sido objeto de abundantes estudios. Sin embargo, sobre cómo se ha desarrollado históricamente el proceso de negociación necesario para el diseño de tales normas, el asunto en el que está centrada la atención de este artículo, es poco lo que se sabe. En el artículo se utiliza el caso de la Acequia Real del Júcar, que tras ser construida en el siglo XIII experimentó una ampliación, a principios del siglo XIX, que la convirtió en el mayor de los sistemas de riego existentes en la España de momento. Como resultado de esa ampliación, proliferaron los enfrentamientos entre los viejos y los nuevos regantes, el ambiente de cooperación entre los usuarios se desvaneció y fue necesario elaborar una nueva normativa. Para que el consenso pudiera reconstruirse, fue básica la presencia de dos factores: el hecho de que los regantes dispusieran de una elevada autonomía para rediseñar las instituciones, y la intervención de árbitros externos (que asumieron ese papel en representación de las autoridades políticas estatales).

\footnotetext{
Salvador Calatayud es profesor titular del Departamento de Análisis Económico de la Universidad de Valencia. Dirección para correspondència: Departamento de Análisis Económico, Facultad de Economía, Avenida de los Naranjos, s/n, 46022-Valencia. Correo electrónico: salvador.calatayud@uv.es.

Samuel Garrido es profesor Titular del Departamento de Economía de la Universidad Jaume I de Castellón. Dirección para correspondencia: Departamento de Economía, Universidad Jaume I de Castellón, Campus del Riu Sec, s/n, E-12071-Castellón de la Plana. Correo electrónico: Samuel.Garrido@eco.uji.es.

1 Este trabajo se enmarca en los Proyectos de Investigación SEJ2007-60845, HAR201020684-C02-01 y ECO2009-10739.
} 


\title{
Palabras Clave: Regadío. Agua. Comunidades de regantes. Insti- tuciones. Valencia.
}

\section{THE NEGOTIATION OF RULES AND STATE INTERVENTION IN IRRIGATION MANAGE- MENT: THE JÚCAR CANAL IN THE MID-19 ${ }^{\mathrm{TH}}$ CENTURY}

\begin{abstract}
The way the rules for distributing water work in irrigation communities has been the object of numerous studies. Yet, little is known about how the negotiation process that is required to design such rules has developed historically, which is what this article focuses on. Specifically, the case of the Jucar Canal, which was built in the $13^{\text {th }}$ century and went on to become the largest irrigation system in Spain after undergoing an extension in the early $19^{\text {th }}$ century. As a result of said extension, there were many clashes between the old and the new irrigators, the climate of cooperation between users diminished and it became necessary to draw up a new set of regulations. Two crucial factors allowed a new agreement to be reached: the fact that the irrigators were able to redesign the institutions with a high degree of autonomy, and the intervention of representatives of the political authorities of the State who adopted the role of external arbitrators.
\end{abstract}

KEY WORDS: Irrigation. Water. Irrigation communities. Institutions. Valencia.

En los estudios sobre las instituciones que rigen el uso agrario del agua es frecuente defender que la participación de los usuarios en la elaboración de las normas es una condición necesaria para alcanzar una gestión eficaz y sostenible. Se aducen dos razones para ello. Por un lado, las normas han de ser adecuadas a las condiciones locales específicas que singularizan cada sistema de riego, por lo que se requiere contar con aquellos que poseen la información específica que es, frecuentemente, de carácter local. Por otro, los usuarios han de considerar legítimas las normas para respetarlas y será más probable que las consideren legítimas si han participado en su elaboración ${ }^{2}$. Sin embargo, también se ha destacado que la elaboración de las normas no depende tan solo de los regantes, sino que se produce la intervención de poderes externos (en especial del Estado), sobre todo cuando hay intereses en conflicto o proble-

2 Ostrom, Elinor, Governing the Commons. The Evolution of Institutions for Collective Action, Cambridge, C. University Press, 1990; Crafting Institutions for Self-Governing Irrigation Systems, San Francisco, Institute for Contemporary Studies, 1992; y Understanding Institutional Diversity, Princeton, P. University Press, 2005. TANG, Shui Yan, Institutions and Collective Action. Self-Governance in Irrigation, San Francisco, Institute for Contemporary Studies, 1992. Bardhan, Pranab, «Distributive Conflicts, Collective Action, and Institutional Economics», en Meier, G. M. y Stiglitz, J.E. (eds.), Frontiers of Development Economics. The Future in Perspective, Oxford, O. University Press, 2001, págs. 269-290. 
mas de coordinación con otros usuarios. La autonomía de los regantes, por tanto, es solo parcial ${ }^{3}$.

Así sucedió en el regadío valenciano, donde han existido históricamente varios límites a la participación del conjunto de los regantes en la gestión de los canales: exclusión de los cultivadores no propietarios; intervención de los municipios en la administración del agua; papel limitado de las asambleas de propietarios; etc 4 . Sin embargo, se produjo también lo que podríamos llamar una participación indirecta en el diseño de las normas: estas habían de ser percibidas como justas por parte de los usuarios finales del agua, que en muchos casos eran arrendatarios que no podían participar en absoluto en su elaboración. Tenía que alcanzarse un cierto consenso, pues, que incluyera también a quienes no tenían derecho a participar en el diseño de la normativa. Simultáneamente, las autoridades políticas intervinieron a menudo en la elaboración y modificación de las reglas, en particular en aquello que vinculaba las comunidades de regantes con el «exterior». Así pues, la coerción fue otro componente fundamental.

Este artículo pretende explorar las formas que adoptaba en la práctica la interacción entre usuarios del agua y poder político, con el objetivo de determinar el alcance que tenía la autonomía de los regantes ${ }^{5}$. Al analizar esta cuestión, fundamental en todo sistema de riego, podremos conocer de qué manera los agricultores resolvieron los problemas de gestión colectiva del agua provocados por la consolidación y expansión de la agricultura intensiva y comercial en el siglo XIX.

3 SAleth R. Maria y DinaR, Ariel, The Institutional Economics of Water. A Cross Country Analysis of Institutions and Performance, Cheltenham, Edward Elgar, 2004, págs. 42-43; LAM, Wai Fung, «Institutional Design of Public Agencies and Coproduction: A Study of Irrigation Associations in Taiwan», World Development, 24, 6, 1996, págs. 1039-1054; AGRAWAl, Arun y GIBSON, Clark C., «Enchantment and Disenchantment: The Role of Community in Natural Resource Conservation», World Development, vol. 27, 4, 1999, págs. 629-649.

4 GARrido, Samuel, «Las instituciones de riego en la España del Este. Una reflexión a la luz de la obra de Elinor Ostrom», Historia Agraria, 53, 2011, págs. 13-42.

5 La evolución de las instituciones jurídicas que han regulado el uso del agua en España cuenta con una extensa bibliografía. Véanse: LALINDE ABADÍA, J. «La consideración jurídica de las aguas en el Derecho Medieval Hispánico», Anales de la Facultad de Derecho (Universidad de La Laguna), 6 (1968), págs. 43-94; Morales PAYÁn, M. Á. y GóMEz DíAZ, D., «Defensa de los Tribunales de agua por los constitucionalistas de 1812», Los cultivos bajo plástico. Actas. Primer Congreso Europeo de Derecho Agrario, Instituto de Estudios Almerienses, Almería, 1995, págs. 295-311; JORDANA DE POZAS, L., «La evolución del derecho de las aguas en España y en otros países», Revista de Administración Pública, 37, 1962, págs. 961; GuAitA, A., "Acerca de la naturaleza jurídica de los jurados de riego», Primer Congreso Nacional de derecho de aguas, Murcia, 1984, págs. 493-497; GALlego AnABitarTe, A., MenÉndez ReXACH, A. y DíAz LeMA, J.M., El derecho de aguas en España, Madrid, Ministerio de Obras Públicas y Urbanismo, 1986, especialmente vol. 2. 
Para ello, el trabajo se ha centrado en un sistema de riego suficientemente importante y de larga trayectoria, como era la Acequia Real del Júcar, en la provincia de Valencia, y en un momento muy significativo, las décadas centrales del siglo XIX, cuando se acababa de producir una ampliación del canal que, prácticamente, dobló su tamaño y sus prestaciones y alteró las relaciones internas entre los regantes. Como consecuencia de ello, el canal hubo de afrontar un proceso de reelaboración de las ordenanzas que regían el riego desde la Edad Media. Esta refundación fue impulsada por la autoridad del Estado, pero trató de obtener el consenso de los usuarios y alumbró un sistema de riego bastante diferente del existente hasta ese momento.

\section{CAMBIO de ESCALA: LA AMPLIACión de LA ACEQUia ENTRE 1766 Y 1815}

La Acequia Real del Júcar (denominada Acequia de Alcira antes del siglo XIX) es un ejemplo claro de los sistemas de riego de gran tamaño y elevado número de usuarios, que requieren soluciones organizativas peculiares, diferentes a las de otros sistemas de ámbito exclusivamente local. Los estudios realizados desde la perspectiva institucional afirman que la principal de las peculiaridades de estos sistemas es la coexistencia de diferentes niveles de acuerdos (multilevel arrangements) ${ }^{6}$ : normas particulares de cada uno de los subsistemas que componen el conjunto y normas generales que atañen a los elementos hidráulicos compartidos, al uso del acuífero del que depende el riego y a la coordinación con instancias exteriores.

La acequia de Alcira fue construida entre 1258 y 1269 como parte de la estrategia de la monarquía catalano-aragonesa para fijar a los repobladores cristianos en las tierras recién conquistadas al sur de la ciudad de Valencia ${ }^{7}$. El canal principal fue financiado por el rey, mientras los regantes pagaron las obras secundarias. Sin embargo, el ambicioso proyecto inicial, que llevaba el canal hasta Albal (unos $54 \mathrm{~km}$ ), quedó reducido a la mitad, con final en Algemesí $(26 \mathrm{~km})$. Pese a todo, se trataba de una ampliación muy sustancial del regadío preexistente.

La monarquía renunció definitivamente a financiar la prolongación cuando, en 1404, Martín I el Humano promulgó un Privilegio que otorgaba permiso a quien emprendiera la continuación de la acequia y fijaba las condiciones para hacerlo. Sin embargo, ningún particular, grupo de regantes o pueblo se acogió a esta posibilidad durante más de tres siglos: las dimensiones de la empresa y la oposición de los regantes de la parte ya construida inhibieron las

\footnotetext{
6 TANG, S. Y., Institutions and Collective Action, págs. 23-24 y 32-33.

7 Peris AlbentosA, Tomàs, La Séquia Reial del Xúquer (1258-1847). Síntesi històrica $i$ aportacions documentals, Alcira, Germania, 1995, págs. 24-25.
} 
potenciales iniciativas, hasta que el duque de Híjar, señor de Sollana —uno de los pueblos que habían de acceder al riego con la prolongación - se acogió en 1760 al Privilegio citado 8 .

Durante los cinco siglos transcurridos entre la construcción de la acequia y la ampliación que iba a acometer el de Híjar, la gestión del riego se basó en una agregación de normas de diferente origen y entidad, que se superponían y complementaban y que habían ido surgiendo a lo largo del tiempo como respuesta a los cambios en las condiciones en que se desarrollaba el riego ${ }^{9}$.

Hubo dos recopilaciones de normas, elaboradas en 1350 y 1620 , que constituyeron marcos muy generales y poco detallados pero que, por su larga vigencia (no habría otras ordenanzas hasta 1845), debieron resultar suficientes para regular los aspectos más básicos del sistema. Al lado de esta especie de «leyes generales», existieron también disposiciones penales escritas, como las de 1596; normas consuetudinarias, entre las cuales se encontraban las decisiones que tomaban los acequieros y que quedaban incorporadas a la práctica del riego; decisiones adoptadas en las reuniones de regantes; y disposiciones del Estado que afectaban a grupos específicos de regantes o a municipios (por ejemplo, las que trataron de resolver las pugnas entre Alcira y Algemesí o entre el señorío de Alberique, poblado por moriscos hasta 1609, y los pueblos cristianos de realengo).

La autonomía de los regantes para organizarse y decidir las condiciones de uso del agua fue muy amplia durante estos siglos, a pesar de que la acequia formaba parte del Real Patrimonio. A excepción del periodo anterior a 1350, durante el cual la administración estuvo en manos de funcionarios de la monarquía, el Estado apenas intervino en el funcionamiento de la acequia ${ }^{10}$. Cuando lo hacía, era para arbitrar ante conflictos entre regantes o con propósitos recaudatorios, ofreciendo concesiones a cambio de dinero. Se cumpía aquí, pues, el principio de la gestión autónoma a cargo de los interesados en el riego.

Esta gestión hacía recaer la toma de decisiones (al menos, las que afectaban a algunos aspectos del gobierno de la acequia) sobre una asamblea, el Consejo General de Regantes, en la que participaban todos los usuarios del riego con un voto por persona. Sin embargo, esta forma de gobierno, participativa y abierta sobre el papel, quedaba limitada en la práctica por el hecho de que había otros órganos más restringidos que decidían previamente las cues-

8 Pedro P. Alcántara Fadrique Fernández de Híjar, duque de Híjar, pertenecía a la alta nobleza española. Era sobrino del conde de Aranda y participó en iniciativas ilustradas, por ejemplo en la financiación de la Sociedad Económica de Amigos del País de Zaragoza.

9 Peris Albentosa, T., La Séquia Reial, pág. 62; y Regadio, producción y poder en la Ribera del Xúquer (La Acequia Real de Alzira, 1258-1847), Valencia, Generalitat Valenciana y Confederación Hidrográfica del Júcar, 1992, págs. 170 y ss.

10 Peris Albentosa, T., La Séquia Reial, págs. 70-73. 
tiones que habían de debatirse en las asambleas ${ }^{11}$. Además, la concurrencia al efectiva en el Consejo General era muy limitada, de manera que solo los miembros de las élites locales acudían a las convocatorias y votaban las resoluciones. Por tanto, el gobierno efectivo del riego era acentuadamente oligárquico. Por otro lado, la administración cotidiana del canal correspondía al acequiero, un funcionario asalariado con un considerable poder de decisión, que era elegido entre los «caballeros» y ciudadanos de los dos pueblos principales que utilizaban la acequia, Alcira y Algemesí. La corrupción y los abusos de poder acompañaron, a menudo, este entramado organizativo, pero no parecen haber puesto en peligro en ningún momento la continuidad del riego ni un consenso básico en torno a los procesos administrativos. En algunos momentos, los conflictos que se derivaron de todo ello forzaron la intervención de la monarquía y las ordenanzas de 1620 fueron resultado, precisamente, de una de estas intervenciones destinada a reequilibrar la concentración de poder en manos de las élites agrarias de Alcira, dominantes hasta ese momento y ahora cuestionadas por el ascenso de otros sectores terratenientes en los pueblos vecinos.

La continuidad, no exenta de cambios, de estas características durante siglos está relacionada con el hecho de que las dimensiones de la acequia se modificaban lentamente. El crecimiento de las tierras regadas fue muy pausado: en el siglo que va de 1673 a 1767 la superficie pasó de 3.991 hectáreas a 5.495 , lo que significa un incremento medio anual de 16 hectáreas. Este ritmo de crecimiento relativamente lento parece haber contribuido a la estabilidad institucional. Frente a esta situación, la ampliación del canal emprendida a finales del siglo XVIII y realizada en un corto periodo de tiempo tendría un impacto traumático sobre la organización del sistema. Todas y cada una de las instituciones formales o informales que regían el funcionamiento de la acequia se vieron alteradas por este cambio de escala, que casi duplicaría la superficie regada y la cifra de usuarios.

En 1766, el duque de Híjar inició las obras de continuación de la acequia. El proyecto, inicialmente concebido para conducir el agua a su señorío de Sollana, se extendió finalmente a otros nueve pueblos y dio lugar a una nueva y amplia área de riego, situada al norte del viejo perímetro y que llegaba prácticamente hasta las huertas del Turia, en las proximidades de la ciudad de Valencia. Los regantes de la acequia histórica, que inicialmente habían aceptado este proyecto, muy pronto se opusieron a la prolongación, una actitud que derivó en motín en algún caso. Ante esta situación, la viabilidad de la obra se vio amenazada y solo fue asegurada por el apoyo y la intervención decidida del Estado, que asumió la iniciativa de Híjar como parte de la políti-

11 Ibidem, págs. 66 y ss. 
ca de estímulo de las obras hidráulicas durante el reinado de Carlos III. Para ello, el Estado nombró un funcionario ajeno al área de riego, que se encargaría de llevar a término las obras y administrar el conjunto de la acequia durante un periodo que habría de prolongarse hasta 1839 . Ello representó una alteración drástica de la manera de dirigir el canal: la burocracia estatal del absolutismo entraba en el gobierno de la acequia y rompía con la autonomía tradicional de los regantes. De esta experiencia quedaría una especie de memoria histórica que, mucho tiempo después, todavía identificaba este periodo intervencionista con una era de autoritarismo y tiranía ${ }^{12}$.

CUADRO 1. CAMBIOS EN EL TAMAÑO Y LAS CARACTERÍSTICAS DE LA ACEQUIA REAL DEL JÚCAR

\begin{tabular}{|l|c|c|}
\cline { 2 - 3 } \multicolumn{1}{c|}{} & $c a .1767$ & $c a .1845$ \\
\hline Superficie regada (Hectáreas) & 5.495 & $\begin{array}{c}12.735 \\
1 .^{\text {a }} \text { sección } 6.497 \\
2 .^{\text {a }} \text { sección } 6.238\end{array}$ \\
\hline Número de municipios & 11 & 21 \\
\hline $\begin{array}{l}\text { Número de propietarios } \\
\text { de tierras regadas }(*)\end{array}$ & $\sim 2.000$ & 10.915 \\
\hline Cultivos predominantes $(\%)(* *)$ & $\begin{array}{c}\text { Huerta } 65 \\
\text { Moreras 30 }\end{array}$ & $\begin{array}{c}\text { Huerta } 54 \\
\text { Arroz 46 }\end{array}$ \\
\hline
\end{tabular}

(*) La cifra de 1767 corresponde a los valores medios del siglo previo. La de después de 1845 corresponde a 1887.

(**) Los valores de 1767 corresponden a Alcira en 1762.

Fuente: Peris AlbentosA, T., La Séquia Reial, pág. 61; y Regadío, producción, pág. 1992, pág. 60; CALATAYUD, Salvador, «El conreu cobejat: arròs i transformacions agràries al litoral valencià, 1800-1870», en Nicolás, M. (ed.), Bernat i Baldoví i el seu temps, Valencia, Universitat de València, 2002, págs. 113-134.

Cuando finalizaron las obras en 1815, el viejo canal había ampliado sustancialmente sus dimensiones, con el consiguiente aumento del número de agentes y pueblos implicados. El sistema de riego que resultaba de todo ello era muy distinto del tradicional, como puede verse en el cuadro 1. Las diferencias respecto al pasado iban más allá del cambio de dimensiones: la acequia de 1845 integraba situaciones sociales y organizativas muy heterogéneas, especialmente el contraste entre los pueblos con tradición de gestión

12 García Monerris, Carmen, La Corona contra la historia. José Canga Argüelles y la reforma del Real Patrimonio valenciano, Valencia, Publicacions de la Universitat, 2005, pág. 210. 
colectiva del riego y los pueblos «clientes» de una especie de empresario de riego que era el duque de Híjar. El resultado no era necesariamente perjudicial para los antiguos regantes, que se beneficiaban del aumento de caudal en la acequia producido por la ampliación del azud y del canal principal, obras que había costeado Híjar. De este modo, la superficie regada también pudo ampliarse en las antiguas comunidades aguas arriba, en muchos casos de manera ilegal ${ }^{13}$.

Los inicios del funcionamento del canal ampliado tuvieron lugar en medio de profundas conmociones sociales y políticas. La prolongada etapa de inestabilidad política durante el proceso de la revolución liberal produjo un cuestionamiento de la autoridad también en los sistemas de riego, de manera que, en muchos de ellos, se multiplicaron las dificultades para hacer cumplir las normas en vigor y para limitar el acceso fraudulento al agua, este último uno de los puntos críticos de todo sistema de riego. Al mismo tiempo se estaba remodelando la estructura de propiedad de la tierra, de la que resultaría una nueva jerarquía social agraria: desaparición de la propiedad eclesiástica, que había sido importante en el área regada por la Acequia Real; abolición de los señoríos y, por tanto, mengua en la capacidad de los señores para controlar la organización del riego en los pueblos de su dominio; nuevas entradas de capital urbano en la propiedad de la tierra. Cambiaba también la configuración del Estado, con la creación de la figura del jefe político provincial, brazo ejecutor directo del gobierno central; la de un nuevo régimen municipal; y la implantación de la representación política, aunque fuera censitaria. Y todo ello simultáneamente al crecimiento demográfico y la consiguiente presión sobre la superficie regada y la sustitución de cultivos en favor del arroz, un producto beneficiado por los cambios en los precios relativos de las cosechas.

El impacto de este conjunto de cambios sobre el uso del agua fue muy visible. Hacia 1840, el riego se había vuelto más incierto y difícil. Cañaverales y maleza invadían el trazado del canal y los desprendimientos de tierra y roturas dificultaban el paso del agua ${ }^{14}$. La extraordinaria fragilidad de estos sistemas de riego, en los cuales la mayor parte de la infraestructura era de tierra y barro, exigía, como condición básica para un funcionamiento eficaz, trabajos regulares de mantenimento y reconstrucción. Una de las consecuencias de las tensiones que experimentó la sociedad rural durante las décadas de la revolución liberal fue el abandono parcial de estas labores, porque el cuestionamento de las jerarquías tradicionales y los efectos de la crisis agraria sobre la ca-

13 Archivo de la Acequia Real del Júcar (a partir de aquí AARJ), c-190, exp. 5, 1818.

14 Proyecto de Reglamento que por orden de D. Antonio González Madroño, Baile general del Real Patrimonio de Valencia, ha formado el Síndico Procurador General de la comunidad de regantes de dicha real acequia, para la monda y desbroze de la misma, Valencia, Imp. Ferrer de Orga, 1838, pág. 1. 
pacidad de gasto de los agricultores debieron retraer el compromiso colectivo que ello requería. La autoridad del Baile del Real Patrimonio, que había asumido la administración de la acequia una vez finalizada la construcción, no bastó para obtener la cooperación de regantes y ayuntamientos, al tiempo que la carencia de normas e instituciones adecuadas a la nueva situación creaba una gran incertidumbre. En estas circunstancias, sería la progresiva consolidación del nuevo ordenamiento liberal la que favorecería la restauración del consenso.

La reconstrucción institucional se inició cuando, en 1839, el jefe político sustituyó al Baile en la dirección del canal. Con mayor legitimidad política y apoyo gubernamental, la nueva autoridad hizo frente al deterioro organizativo y a la ausencia de normas consensuadas. A principios de la década de los cuarenta, era el jefe político quien establecía cada año el reparto del agua y aseguraba un orden precario (enviando en ocasiones fuerza armada para asegurar el riego), no sin protestas de diferentes grupos de regantes. El jefe político envió técnicos a estudiar la situación del canal y la información recabada le permitió concluir que todas las partes violaban las concesiones legales que tenían asignadas. Los pueblos de la primitiva acequia, aprovechando su posición en la cabecera del canal, captaban más agua de la que les correspondía. Por su parte, en los pueblos de nuevo riego, la superficie beneficiada por el agua había crecido mucho más allá de lo establecido en los planes originarios de Híjar. Además, varios años sucesivos de bajo caudal en el río y el mal estado de la infraestructura habían agravado la pugna desesperada por el agua. La causa última de todo ello parecía clara: «... no existe una concordia, una ley armónica y reguladora de derechos y obligaciones» ${ }^{15}$.

Las normas del pasado resultaban inadecuadas para un sistema de riego sustancialmente diferente. Si en los siglos anteriores «...la precisión de trabajar de mancomun obligó a dichos pueblos regantes a unirse bajo ciertos pactos, que aunque sencillos e imperfectos, eran suficientes por entonces para disfrutar del agua que necesitaban» ${ }^{16}$, ahora la extensión y complejidad del canal exigían la renovación de aquellos acuerdos. Además, el hecho de que el cambio hubiera sido decidido y ejecutado por la autoridad externa, y no por los mismos regantes, resultó letal para los mecanismos de cooperación. Tras imponer un incremento importante de quienes tenían derecho al empleo del agua, en contra de la opinión de los usuarios establecidos, se hizo necesario prolongar la intervención mediadora del Estado.

${ }^{15}$ Copia del Informe del Sr. Jefe Superior Político de esta provincia y resolución tomada en los expedientes de D. Alejandro Aznar y D. Pascual Testor sobre reparto de las aguas de la Acequia Real de Alcira y la del Proyecto en el año 1842, Alcira, Imp. S. Lledó, 1932, pág. 10.

${ }_{16}$ Proyecto de Ordenanzas para el gobierno de la Acequia de Alcira redactado de orden del Sr. Jefe Superior Político de esta provincia D. Miguel Antonio Camacho por el oficial primero D. Pedro López Chapí, Valencia, Imp. Ferrer de Orga, 1842, pág. 1. 


\section{EL PROCESO DE NEGOCIACIÓN DE LAS NUEVAS NORMAS, 1815-1845}

La necesidad de unas normas que hicieran viable el canal ampliado no era compartida por el conjunto de los regantes. En los sistemas de riego, una de las líneas de fractura más habituales es la que separa - y, eventualmente, enfrenta- a quienes tienen sus parcelas en los primeros tramos del canal principal y a los que las tienen al final. Estos últimos son los más interesados en que las reglas estén muy claramente especificadas y en que los trabajos de mantenimiento se realicen de manera adecuada. Ello es especialmente aplicable al caso estudiado. Mientras los regantes de la segunda mitad del canal pedían, de manera urgente, un cambio en la normativa, los regantes antiguos, situados aguas arriba, se resistían a que ello sucediera, porque las viejas reglas resultaban beneficiosas para ellos y la ausencia de normas generales también los favorecía, como consecuencia de disfrutar de ventajas físicas en el acceso al agua. En estas condiciones, fue el Estado el impulsor del cambio normativo y el que forzó a los diferentes agentes a negociarlo bajo su supervisión. Sin embargo, no fue un proceso fácil. Antes de conseguir el establecimiento, en 1844, de unas ordenanzas nuevas hubo que afrontar varios intentos fracasados.

Durante las tres décadas previas se habían presentado cinco proyectos diferentes de ordenanzas, sin que se consiguiera consensuarlas ni aprobarlas. Estos proyectos sucesivos tenían orientaciones muy diferentes, influidas por los contextos políticos cambiantes bajo los cuales se elaboraron. El redactado en 1815, bajo la reacción absolutista, consolidaba el gobierno de la acequia por un poder externo y dejaba en una posición subordinada a las agrupaciones de regantes ${ }^{17}$. Estas no lo aceptaron y el Estado no consiguió imponerlo. El segundo proyecto, presentado en 1822 en un contexto político muy distinto, suprimía toda autoridad por encima de los regantes y privilegiaba a los de las antiguas comunidades y a los ayuntamientos. Se discutió públicamente en todos los pueblos mediante reuniones abiertas de todos los regantes, pero el giro político del año siguiente dejó en suspenso la iniciativa ${ }^{18}$. Más adelante, en 1835 y 1838 , se elaboraron otros borradores de ordenanzas que no llegaron a ser discutidos, mientras las tensiones entre los dos tramos de la acequia crecían y las autoridades externas no conseguían pacificar la gestión del agua.

Esta situación exigía una intervención cotidiana del poder político, de manera que, a la altura de 1842, los problemas de riego en esta y otras acequias

17 Peris Albentosa, T., La Séquia Reial, págs. 186-187. También: AARJ, c. 190, exp. 5, «Observaciones al Proyecto de Ordenanzas formado por los cinco Electos de la Antigua Comunidad de Regantes en quanto toca a la Acequia del proyecto y derechos de S.E. el Duque de Híjar».

${ }_{18}$ Proyecto de Ordenanzas para el gobierno de la acequia llamada de Alcira, Valencia, Imp. de Venancio Oliveres, 1822. También AARJ, c-190, exp. 7. 
desbordaban la acción administrativa del jefe político y absorbían buena parte de los recursos humanos de la autoridad provincial. El Estado aumentó su implicación y forzó el cambio normativo cuando Espartero decretó la obligación de redactar las ordenanzas en un plazo breve. De ello resultó un borrador redactado por funcionarios del gobierno civil en 1842. En este proyecto quedaba reforzada la postura de los regantes antiguos, a quienes se restituían las atribuciones que venía desempeñando la autoridad externa desde hacía décadas. A los ayuntamientos se les concedía una gran capacidad de intervención, mientras la participación de los regantes en la dirección del canal se extendía a una parte muy amplia de los propietarios (podían ser directivos los poseedores de más de 1,6 hectáreas) e incluso a los arrendatarios que cultivaran más de 2,5 hectáreas ${ }^{19}$. Este proyecto de ordenanzas, como los anteriores, no consiguió la aceptación de todos: fue rechazado por los regantes de la segunda parte del canal y por el duque de Híjar.

El intento definitivo vendría en 1844 y fue precedido de una nueva inspección de la acequia, ordenada por el jefe político y realizada por personal ajeno al canal. Este estudio confirmó el mal estado de mantenimiento, las importantes pérdidas de agua durante la conducción y la situación precaria en que se encontraba el riego en el segundo tramo ${ }^{20}$. Con esta información como base, el Ministerio de la Gobernación dio todas las atribuciones al representante provincial del Gobierno para dirigir la redacción de nuevas ordenanzas y forzar a las partes a reunirse. Y sancionó esta capacidad con la promulgación de tres decretos en los que se establecían los principios que debían inspirar las normas nuevas y, en especial, la cuestión central: la consideración de las dos partes de la acequia como un único canal con los mismos derechos para todos los regantes ${ }^{21}$.

La negociación que, finalmente, alumbró las nuevas normas se produjo en dos niveles diferentes. Por un lado, hubo lo que podríamos denominar una negociación indirecta, un debate público en el cual las partes enfrentadas se dirigían a la autoridad política y a la opinión pública a través de escritos, reclamaciones, etc., a veces editados para facilitar su difusión y que aspiraban a influir en las decisiones finales. Por otra parte, hubo también una discusión directa artículo por artículo en reuniones presididas por el Jefe Político.

19 Proyecto de Ordenanzas para el gobierno de la Acequia de Alcira. El contexto político durante estos años en los que el progresismo arraigó profundamente en la zona de Alcira debe tenerse en cuenta para entender el activismo con el que la antigua comunidad se resistió a la incorporación del segundo tramo del canal con los mismos derechos que los viejos regantes; cf. RODRíGUEZ SERRES, Fernando, «Aproximación a la vida política alzireña durante la regencia de Espartero (1840-1843)», Al-Gezira, 6, 1990, págs. 309-341.

20 Justificación del agua a perder en la acequia de Alcira en lo que va del presente año de 1844, Valencia, M. López, 1844.

21 Real Orden del 1 y del 9 de marzo y del 2 de julio de 1844; AARJ, c. 189, exp. 16; Archivo de la Diputación Provincial de Valencia (en adelante ADPV), E.3.1., c. 49, exp. 818. 
En lo que respecta a la primera, se trató de la confrontación pública de dos relatos opuestos que habían ido elaborando las dos partes durante el conflictivo periodo anterior y que trataban de justificar las aspiraciones al control del agua a partir de las necesidades presentes, pero también en base a una apelación a argumentos históricos, presentados como demostración de las demandas respectivas. En los sistemas de riego tradicionales del territorio valenciano, el pasado era una reserva de datos, seleccionados o «inventados» con propósitos legitimadores; no solo se referían a la costumbre sino también a concesiones del derecho a extraer agua de los ríos, realizadas por los monarcas medievales: Jaime I para unos, Martín I para los otros, pero en los dos casos presentados como reyes benefactores por su impulso al regadío. En esta amalgama de elementos de diferente origen, había también un espacio para los principios fundados en la propiedad privada sobre las tierras regadas, sobre la riqueza creada con el uso del agua y sobre las canalizaciones e infraestructuras: para ambas partes, el agua que les correspondía era una propiedad «sagrada e inviolable», aun cuando se justificara por concesiones medievales. Finalmente, se aducían argumentos más productivistas cuando, por ejemplo, se cuantificaban las pérdidas de cosechas en la parte final de la acequia causadas por la falta de ordenación en el volumen de agua disponible para estos regantes ${ }^{22}$.

Los pueblos que obtenían el riego de la antigua acequia de Alcira consideraban que su uso del agua, anterior en el tiempo, les otorgaba derechos preeminentes sobre los regantes incorporados con posterioridad. No había, pues, que alterar la administración de la acequia, que debía seguir rigiéndose por el «... contrato celebrado por los vecinos de Alcira con el rey D. Jaime el $\left.1^{\circ} \ldots\right\rangle^{23}$. Desde esta perspectiva, los regantes nuevos solo tendrían derecho al agua sobrante de la primera parte del canal y, en consecuencia, no podían formar parte de la dirección en igualdad de atribuciones. Rechazaban, pues, la decisión del gobierno de unificar plenamente la gestión de ambas partes del canal. En la práctica, ello implicaba dejar la acequia en un estado precario, con regantes (aproximadamente la mitad de ellos) excluidos de la toma de decisiones, lo que habría comprometido la viabilidad de la nueva área de riego.

Tanto para los nuevos regantes como para el duque de Híjar y el Real Patrimonio (que era propietario eminente de las «fronteras» de la Albufera, muy

22 Para el área regada en Silla las pérdidas en 1843 se calcularon en 2,9 millones de reales; ADPV, E.3.1., c. 48, exp. 805. En 1842 se evaluaban las pérdidas totales del segundo tramo, provocadas por la falta de agua, en unos 6 millones de rv. Se trata de cálculos realizados por peritos para unas diligencias judiciales. La cifra de seis millones equivalía al $89 \%$ del valor anual de los arriendos de todas las tierras que regaban del segundo tramo de la acequia; véase CAlATAYUd, S., Millán J. y ROMERO, M. ${ }^{a}$ C., «El rentismo nobiliario en la agricultura valenciana en el siglo XIX», Revista de Historia Económica, XVIII, 1, 2000, pág. 106.

${ }^{23}$ ADPV, c. 52, exp. 870. 
beneficiadas por la prolongación de la acequia), la concesión para construir el segundo tramo comportaba el derecho a una determinada cantidad de agua del Júcar, separada de la que correspondía a la zona de riego antiguo ${ }^{24}$. Este volumen de agua — que tenía que discurrir, sin embargo, por el mismo canalhabía de ser fijado con precisión y estaría definido por el volumen incorporado a la acequia a través de la compuerta construida por el duque a finales del siglo XVIII. La propiedad sobre esta obra proporcionaba el derecho sobre el agua. Para asegurar estas condiciones, los mecanismos de administración de la acequia debían integrar los dos tramos con los mismos derechos y atribuciones. Insistían en excluir toda intervención de los ayuntamientos a partir de la idea de que solo los regantes podían decidir sobre el agua: «El interés individual es el que mueve al hombre y el que dirige sus operaciones. Nadie mejor que los regantes propietarios de tierras pueden elegir personas que correspondan a la confianza que en ellas se deposite» ${ }^{25}$. Para estos poderosos terratenientes y dueños del dominio directo, la consolidación del nuevo regadío exigía una ruptura con la tradicional preeminencia de los municipios y, en especial, con el de Alcira, muy favorecido por el sistema tradicional de gestión ${ }^{26}$.

Ambas posturas contrapuestas implicaban también visiones distintas sobre el grado de fijación de los mecanismos hidráulicos. Los regantes nuevos, que compartían un caudal que otros ya utilizaban previamente y lo hacían desde una posición débil por encontrarse aguas abajo, aspiraban a la máxima institucionalización de su acceso al agua. Planteaban, por ello, cuestiones centrales en la organización de todo sistema de riego que problematizaban las convenciones no escritas que, para los regantes tradicionales, habían presidido el uso del agua. Por ejemplo, al pretender que se estableciera la dotación exacta que les correspondía, los regantes nuevos cuestionaban la pretensión de los del primer tramo de cederles solo los sobrantes, como sucedía en otras acequias construidas en tiempos recientes ${ }^{27}$. Al mismo tiempo, los usuarios del segundo tramo estaban más interesados en los trabajos de mantenimiento de la acequia que los regantes de aguas arriba: el volumen de agua que les llegaba dependía en mayor medida de la correcta realización de la limpieza anual del canal y del resto de obras de reparación. Por ello, defendían la instalación de mojones para establecer los puntos de referencia que habían de servir para limpiar el canal. Algunas de sus propuestas significaban un replanteamiento de la tecnología hidráulica en la que se basaba el sistema de riego. Así, para

24 ADPV, E.3.1., c. 49, exp. 820; y c. 48, exp. 805.

25 AARJ, c-189, exp. 14, 1844.

26 AARJ, c-189, exp. 14.

27 Es el caso de los regadíos de la zona denominada Francs i Extremals en la huerta de Valencia; cf. Lluch, Ferran y Beltrán, Lluis, Las acequias de Francos, Marjales y Extremales de la ciudad de Valencia, Valencia, Ayuntamiento, 1991. 
evitar «... todo esceso y desorden», proponían instalar derivaciones fijas e inmodificables, en lugar de los mecanismos en uso, poco precisos y fácilmente manipulables. Las compuertas, boqueras, etc. debían ser de piedra o metal, tener unas dimensiones fijas que permitieran captar solo el volumen de agua necesaria y poder ser reguladas con precisión. Sin embargo, todo ello exigía medir previamente la cantidad de tierras que regaban de cada derivación. En todo caso, las dimensiones fijadas para los diferentes mecanismos debían recogerse en registros custodiados por la administración del Estado y por los ayuntamientos a fin de poder comprobar, cada año, si se habían producido modificaciones fraudulentas ${ }^{28}$. Se aspiraba así a un grado mayor de codificación de aspectos esenciales del riego, que comportaba elevados costes de instalación y supervisión y un replanteamiento aún mayor de los acuerdos en que se fundaba el sistema ${ }^{29}$.

Frente a estos dos discursos opuestos, la autoridad política tenía su propia posición sobre el modo en que debía gestionarse el canal. Propugnaba la consolidación legal de algunas de las atribuciones que ella misma venía desempeñando, a partir de una comprensión amplia del interés público: «...muchos creen que estas cuestiones son privadas porque sólo se trata de intereses de particulares que pueden gobernarse a su antojo y ésto es un craso error. Estas cuestiones son públicas y si median intereses de particulares, median también intereses públicos de Gobierno ${ }^{30}$. Por ello, el jefe político debía formar parte de la dirección del canal; tener voto en todas las decisiones; aprobar la recaudación de fondos y las obras; intervenir en el nombramiento de los cargos importantes (lo exigían «... razones de política... cuanto menos para evitar que con este nombramiento pueda darse a persona determinada una influencia perjudicial»); autorizar nuevas captaciones de agua; y ser la única instancia para imponer sanciones. Todo lo cual se planteaba en un contexto en el que el representante del gobierno estaba recabando información de todos los pueblos de la provincia sobre las normas de riego que regían en cada lugar, mientras intervenía en muchas de las acequias para imponer cambios y forzar nuevos acuer$\operatorname{dos}^{31}$.

28 Ibidem: las entradas de agua debían conservar «... las mismas exactas pulgadas de diámetro... que serán cotejadas con las que resulten del testimonio que debe obrar en los archivos».

29 Sobre los costes de establecer de forma precisa los derechos de propiedad: EGGERTSSON, Thráinn, El comportamiento económico y las instituciones, Madrid, Alianza, 1995, págs. 95 y ss.

${ }^{30}$ AARJ, c-189, exp. 9.

31 ADPV, c-53, exp. 899; c-56, exp. 921y 931; c-61, exp. 1023. FERRI, Marc, «Reorganización de los regadíos valencianos en el siglo XIX: las ordenanzas liberales de la provincia de Valencia (1835-1850)», Áreas, 17, 1997, págs. 77-89. 
En el contexto de esta confrontación de discursos, se produjo en 1844 la negociación directa de las normas. La iniciativa correspondió al jefe político, que presentó un borrador de ordenanzas y, a continuación, reunió una comisión formada por representantes de los regantes para discutir el texto ${ }^{32}$. Los veintiocho delegados fueron elegidos en asambleas en los pueblos de ambas partes del canal, en las cuales participaron propietarios regantes que, a su vez, habían sido escogidos por los ayuntamientos ${ }^{33}$. Las dos partes del canal contaban con igual número de representantes y entre los elegidos se encontraban miembros de las élites locales, grandes propietarios urbanos y los representantes de la casa de Híjar. Todo ello se hizo, no obstante, al ritmo marcado por el jefe político, que convocaba las reuniones, intervenía en ellas y, con frecuencia, deshacía con su voto los empates en las votaciones.

La mayoría de las normas que propuso la autoridad política en su texto fueron aceptadas sin modificaciones o solo con retoques formales. Hay dos razones que lo explican. Por un lado, las normas afectaban tan solo al canal principal y no entraban en las prácticas administrativas y de reparto del agua que se habían de seguir en cada pueblo, una vez que el agua entrara en las derivaciones respectivas. Se les reconocía así a las diversas comunidades locales una autonomía muy amplia en la organización del riego. Por otro, el redactor del borrador parece haber buscado un cierto equilibrio entre las partes - que comenzaba por la paridad de representantes de los dos tramos de la acequia en todos los órganos de gobierno-, aunque el hecho mismo de cambiar las normas suponía eliminar la preeminencia tradicional de unos y crear derechos nuevos para los otros.

Sin embargo, a pesar de este consenso bastante amplio, hubo discusión sobre algunos puntos importantes y se introdujeron novedades y modificaciones en el curso de los cinco días de reunión. La cuestión que provocó más debate afectaba a los criterios para formar los órganos de gobierno de la acequia: quién debía estar representado y cómo se elegirían los cargos directivos. Tres aspectos básicos dominaron el debate:

En primer lugar, la pretensión de los regantes antiguos de que solo los pueblos pudieran elegir representantes en los futuros órganos de gobierno, lo cual excluía al duque de Híjar. Esto fue rechazado gracias al voto del jefe político, que introducía así al propietario de la segunda parte del canal en la dirección.

En segundo lugar, los representantes del segundo tramo (entre los cuales, como veremos, predominaban los grandes propietarios urbanos) propusieron que la elección la hicieran directamente los regantes, sin participación de los

32 ADPV, E.3.1., caja 57, exp. 955.

33 Como consecuencia de las diferentes orientaciones políticas en los municipios, fueron elegidos algunos representantes progresistas, opuestos al gobierno; ADPV, c. 54, exp. 909. 
ayuntamientos, a lo que se oponían la otra parte y el jefe político, que acabaron consolidando el papel de los municipios en la nueva dirección del canal. Se aprobó un mecanismo de elección que establecía en cada pueblo una especie de colegio electoral compuesto por todos los concejales y por un número igual de mayores propietarios. Este diseño integraba situaciones sociales que eran diferentes en cada lugar, consagrando al mismo tiempo un equilibrio entre élites locales y grandes terratenientes forasteros.

En tercer lugar, se discutió mucho sobre el número de representantes de cada pueblo y se rechazó que fuera proporcional a la superficie regada. Esta posibilidad habría beneficiado a los pueblos grandes, mientras que la representación aprobada - que atribuía un representante a los pueblos pequeños y dos a los grandes - diluía el peso del municipio que había dominado hasta entonces la dirección de la acequia, Alcira. Y, una vez más, la diversidad social de los propietarios regantes se incorporaba a la dirección al establecer que, donde había dos representantes, uno de ellos debía ser vecino y el otro forastero.

Junto a la configuración de los órganos directivos, la otra gran cuestión fue la distribución del agua desde el canal principal a los canales secundarios. Aquí, sin embargo, la discusión fue menor, ya que las normas no establecían los volúmenes de agua sino que remitían, provisionalmente, a la partición vigente («... los usos establecidos y la práctica corriente») ${ }^{34}$. La autoridad política no quiso entrar en una de les cuestiones más sensibles y decisivas del sistema de riego, como era el reparto del agua. Se acordó que la distribución definitiva se establecería según la superficie regada por cada derivación, la calidad de las tierras y el cultivo predominante. Para ello las normas obligaban a elaborar, en el término de un año, un registro de todas las tierras de riego cuya confección estaría dirigida por los nuevos órganos de gobierno que se establecerían, en colaboración con los ayuntamientos de cada pueblo. Este registro habría de ser la herramienta para fundar una nueva distribución del agua y ello suponía la refundación de los acuerdos en que se había basado durante siglos la existencia del canal. Precisamente la trascendencia de esta iniciativa puede explicar que el registro no llegara a materializarse en el plazo establecido y tuviera que esperar durante décadas, aun cuando ello contravenía el artículo 115 de las nuevas ordenanzas. En la práctica, la confección de este documento se convertiría en un campo de batalla más entre los pueblos, la autoridad nueva de la acequia y el gobierno.

Hubo, en cambio, mucha discusión sobre dos puntos específicos que afectaban a la distribución del agua. El primero fue un debate terminológico en el que algunos pusieron mucho interés: se debatió si la cantidad de agua que se asignaría a cada canal secundario sería la «suficiente», como proponía el bo-

${ }^{34}$ ADPV, c. 54, exp. 909, f. 52. 
rrador (y resultó aprobado), o la «conveniente», como apuntaba un representante del primer sector de la acequia. Mientras el primer adjetivo sugería una dotación adaptada a las necesidades estrictas, el segundo parecía apuntar otros criterios que fácilmente podían vincularse a los volúmenes empleados tradicionalmente. El segundo punto de discusión afectaba a la distribución excepcional del agua en tiempos de sequía. Cuando fuera necesario racionar el agua, los regantes antiguos pretendían tener preferencia y así se aprobó con el voto del jefe político. Ello concedía una preeminencia a los derechos tradicionales en una cuestión que no era secundaria, porque la falta de agua era una amenaza frecuente. Sin embargo, cuando las ordenanzas se publicaron unos meses después, este artículo había cambiado radicalmente y se había establecido una distribución por tandeo entre todos los pueblos regantes, que fue la que primaría desde entonces. No sabemos qué indujo esta modificación de lo aprobado por la mayoría, ni conocemos las reacciones que el cambio debió provocar, pero la cuestión plantea el juego de influencias que los regantes del segundo tramo y el propio duque de Híjar debieron poner en marcha frente a una decisión que les perjudicaba.

Sobre otras cuestiones importantes hubo un consenso significativo: la preferencia que se otorgaba al riego sobre los molinos y otros artefactos hidráulicos; el capítulo entero de las sanciones; o la retirada a los ayuntamientos y a Híjar de la facultad de conceder riego a nuevas tierras o agua para nuevos molinos. Por lo que respecta a esta última limitación, sería difícil hacerla respetar, como veremos enseguida, en gran medida a causa del retraso en la elaboración del nuevo censo de tierras. Las tensiones entre los diferentes componentes del canal y la nueva autoridad política no iban a desaparecer en el corto plazo, aun cuando quedaban enmarcadas en el nuevo conjunto normativo.

\section{LA INTERVENCIÓN ESTATAL Y LA DIVERSIDAD SOCIAL DE LOS REGANTES}

Las nuevas normas y su sanción por el poder político (se aprobaron mediante una real orden en 1845) no aseguraron de inmediato el funcionamento cotidiano de la acequia. Desde el primer momento se multiplicaron los conflictos y el gobernador tuvo que intervenir de forma habitual. La primera reunión de la nueva junta general, celebrada un mes después de aprobarse las ordenanzas, ya estuvo presidida por un representante suyo, que forzó la aceptación de los criterios de funcionamiento del nuevo organismo y la elección de todos los cargos ${ }^{35}$. La construcción del consenso fue, por tanto, una labor difícil que no culminaría hasta algunas décadas más tarde. La aplicación de

35 ADPV, c-62, exp. 1050. 
las nuevas Ordenanzas se enfrentaba a multitud de oposiciones. No se trataba solo de la pervivencia de aquellas visiones contrapuestas sobre el funcionamiento de la acequia que venían del pasado. Conflictos nuevos aparecieron en un contexto muy cambiante por lo que respecta a las bases sociales de la propiedad y a la orientación productiva de la agricultura de regadío. La extrema complejidad de este sistema de riego generaba muchas divergencias entre el conjunto de regantes, multiplicaba los enfrentamientos, cuyos protagonistas cambiaban con frecuencia, como también cambiaban las alianzas entre grupos diferentes. Así, encontramos regantes antiguos enfrentados todavía a los incorporados más recientemente, los cuales se aliaban, a veces, con Híjar; encontramos a los pueblos, a través de sus ayuntamientos, en conflicto con la dirección de la acequia; en ocasiones, los propietarios locales en pugna con los terratenientes urbanos; los regantes de la segunda sección enemistados con el duque de Híjar, a quien pagaban por el agua; y, junto a todo ello, encontramos el más universal de los conflictos, el que oponía a quienes usaban el agua sin derecho a ello, o sin respetar las normas, con los regantes cooperativos que se encontraban protegidos por las instituciones de la acequia.

Las cuestiones que fueron objeto, con mayor frecuencia, de la intervención del representante del gobierno nos permiten calibrar los límites de la gestión autónoma del riego y el papel que cumplía la autoridad externa en la regulación y el arbitraje. Podríamos agruparlas en cuatro ámbitos:

Desde el primer momento de la nueva etapa, los antiguos regantes constituyeron una entidad que pretendía una autonomía respecto a los nuevos órganos de dirección: se dieron el nombre de Junta Defensora de la Antigua Comunidad, contaron con fondos propios pocedentes de las cuotas generales que pagaban los regantes del primer tramo y celebraban también reuniones anuales $^{36}$. El Gobernador aceptó esta representación, que intervino en diferentes conflictos, demandas y pleitos durante la década de $1850^{37}$. Había, pues, una estrategia para reconstruir la organización de los regantes tradicionales, que permitía seguir cuestionando, bajo la nueva legalidad, los derechos otorgados a los regantes nuevos y al duque de Híjar. El conflicto de legitimidades continuaba y, con él, la pugna por la «creación» de la tradición del riego en la zona, pero la autoridad política, que toleró esta iniciativa, impidió que llegara a afectar a la aplicación de las normas de 1845.

En segundo lugar, la fijación y recaudación de las cuotas de riego fueron problemas que obligaron a recurrir a la autoridad externa ${ }^{38}$. Las dificultades

36 ADPV, c-62, exp. 1056. Relación del pleito que en grado de apelación sigue la Comunidad de Regantes de la acequia de Alcira con D. José Fadrique Fernández de Híjar, Valencia, Ayoldi, 1855.

37 ADPV, c-62, exp. 1050.

38 ADPV, E.3.1., c. 240, exp. 5437. 
eran múltiples, pero destacan dos: definir las cantidades que debía pagar Híjar, en ausencia de un empadronamiento fiable de la superficie que regaba la segunda parte del canal; y aplicar procedimientos extraordinarios para cobrar a los regantes atrasados en el pago (que representaban, en determinadas coyunturas, cifras elevadas: por ejemplo, 272.000 reales en 1845 , el $38 \%$ del importe total de la recaudación ${ }^{39}$ ), para lo cual era necesaria la fuerza legal de la autoridad política.

En tercer lugar, el arbitraje entre la dirección de la acequia y los pueblos que regaban de ella fue un motivo muy frecuente de intervención del Gobernador. En la peculiar organización de este canal de grandes dimensiones, el papel de los ayuntamientos era clave, pero los límites entre la autoridad general y la particular en cada término municipal no siempre estaban claros y eran objeto recurrente de disputa ${ }^{40}$.

Por último, el arbitraje en las multas impuestas por la acequia ocupó también al gobernador ${ }^{41}$. A veces, los sancionados protestaban por la sanción y la autoridad provincial decidía. Es el caso, por ejemplo, de la reclamación que hizo el conde de Soto Ameno por las multas impuestas a sus arrendatarios de Albal por regar sin derecho; el Gobernador las dejó en suspenso hasta que el conde pudiera demostrar el derecho al riego de las tierras.

La intervención de la autoridad externa venía forzada por la frecuencia de las perturbaciones institucionales en la gestión del riego, que hemos visto en las páginas precedentes. Sin embargo, también fue importante el hecho de que los regantes no constituyeran un grupo homogéneo desde el punto de vista social y económico, es decir, como propietarios de tierras y como productores agrarios. Por el contrario, las desigualdades eran muy marcadas y adquirían diversos significados según los contextos locales. No resulta sencillo atribuir una adscripción social diferenciada a las posturas que, a menudo, entraban en conflicto. En principio, el contencioso más visible, el que enfrentaba a los dos tramos de la acequia, oponía a dos conjuntos de propietarios que, internamente, estaban atravesados por diferenciaciones semejantes en uno y otro caso. Se trataba, pues, de un buen ejemplo de los conflictos de tipo «horizontal» que casi siempre encontramos en las pugnas por el agua. Sin embargo, había rasgos específicos de cada uno de los grupos implicados que nos permiten comprender mejor la dinámica de los sistemas de riego en esta etapa a caballo entre el antiguo régimen y la época liberal. Encabezando las demandas de los pueblos que utilizaban el canal construido por Híjar encontramos a destacados propietarios urbanos, de la ciudad de Valencia. Eran inversores recientes, que habían adquirido tierras incentivados por la puesta en riego y la rápida

\footnotetext{
39 ADPV, c-66, exp. 1127

40 ADPV, E.3.1., c. 221, exp. 5123.

${ }^{41}$ ADPV, E.3.1., c. 141, exp. 3167; y c. 148, exp. 3362.
} 
revalorización que comportaba. En cierto modo, era una propiedad nueva, fruto de la ocupación de las tierras de marjal en los alrededores de la Albufera $\mathrm{y}$, en este sentido, diferente de la que constituía la primitiva área regada. En esta, la posición de las oligarquías locales en la propiedad de la tierra era más sólida y, por ello, los nuevos compradores tenían que adaptarse a estructuras preexistentes en las cuales solo las desamortizaciones permitieron acceder a superficies de cierta entidad. También difería la productividad de las tierras en ambos espacios: frente a las huertas consolidadas por una larga tradición de regadío, muchas de las parcelas nuevas presentaban problemas de drenaje, salinización o falta de adaptación al riego, y, por tanto, proporcionaban rendimientos más bajos ${ }^{42}$. La mayor parte de ellas solo podían dedicarse al arroz, que constituía una opción productiva muy remuneradora durante la mayor parte del siglo XIX, pero también una limitación para otros usos alternativos. A cambio, estas propiedades eran, a menudo, de gran tamaño, en el contexto regional: mientras que en Alcira ninguno de los mayores propietarios que regaban de la acequia no superaban las 25 hectáreas, en las tierras de nuevo riego de Algemesí, por ejemplo, encontramos terratenientes como Felicísimo Llorente con 80 o Vicente Almazán con $40^{43}$.

Estos terratenientes, además, ocupaban lugares muy destacados en la estructura de la propiedad en municipios de dimensiones modestas: la elevada presencia de dueños residentes en la ciudad de Valencia en lugares como Sollana, donde poseían el $61 \%$ de la superficie a mediados del siglo XIX, contrasta con municipios del viejo canal donde esta propiedad era también importante pero muy inferior, como es el caso de Alcira, donde suponía el 30\% por las mismas fechas ${ }^{44}$. En el conjunto de las llamadas «fronteras» de la Albufera -que, en aquel momento, tenían al Real Patrimonio como propietario directo- aristócratas, comerciantes y profesionales liberales de la ciudad de Valencia poseían el $65 \%$ del dominio útil en $1836^{45}$. Estos propietarios se movilizaron reiteradamente para reclamar derechos en la gestión del agua ${ }^{46}$.

42 El duque de Híjar, a la hora de hacer las concesiones de agua, estableció mecanismos de inspección para determinar las condiciones que cada parcela reunía para el riego. No concedía agua si los rendimientos previstos eran muy bajos, ya que la remuneración del duque consistía, como se ha dicho, en una parte de las cosechas.

${ }^{43}$ Cifras correspondientes a una fecha posterior, 1880; ADPV, Fomento-Aguas, leg. 145.

44 Cálculos realizados sobre las tierras regadas por la acequia Real del Júquer, COURTOT, Roland, «Irrigation et proprieté citadine dans l'Acequia Real del Júcar au milieu du XIXe siècle», Etudes Rurales, 45, 1972, pág. 35; CALATAYUD, S., «El conreu cobejat», pág. 32.

${ }^{45}$ García Monerris, Carmen, Rey y Señor. Estudio de un realengo del País Valenciano (La Albufera, 1761-1836), Valencia, Ajuntament, 1985, pág. 215. RoMEO MATEO, M. ${ }^{a}$ Cruz, Entre el orden y la revolución. La formación de la burguesía liberal en la crisis de la monarquía absoluta (1814-1833), Alicante, Instituto de Cultura Juan Gil-Albert, 1993, pág. 50.

46 GARCía Monerris, C., Rey y Señor, págs. 189-191. 
Frente a ellos, que contaban con el apoyo de los labradores de los pueblos respectivos y coincidían muchas veces con las posiciones defendidas por el duque de Híjar, los regantes más antiguos estaban encabezados por oligarquías locales sólidas, como la de Alcira, la ciudad realenga que había dominado el gobierno del canal hasta el siglo XVIII, o la de Alberique, que había destacado en los orígenes de la revolución liberal por la movilización antiseñorial. La presencia de terratenientes urbanos era aquí menor que en los pueblos de la segunda parte del canal y, en muchos casos, su residencia en la ciudad era muy reciente, por lo que todavía mantenían vínculos importantes en el ámbito local.

Por último, estaba la figura del duque de Híjar, en la que convivían significados sociales diferentes, como corresponde a una época de transición. En tanto que señor de Sollana, tuvo que afrontar a finales del Setecientos la oposición de los vasallos a las rentas y a la cabrevación. Sin embargo, la decisión de construir la prolongación de la acequia puede considerarse una iniciativa enraizada en el reformismo ilustrado del que participaba este aristócrata. Valoraciones contemporáneas, como la del viajero y escritor francés Jaubert de Passá (que la historiografía ha asumido muy literalmente), lo considerarían un especulador más que un inversor. Su apelación al Estado para imponer a los antiguos regantes una ampliación del canal que rechazaban, provocaría la condena de su figura en tanto que partícipe del intervencionismo estatal que rigió la acequia durante décadas y que quedó en la memoria oficial de la comunidad de regantes como una muestra de autoritarismo. Sin embargo, la construcción del segundo tramo es un buen ejemplo de las iniciativas privadas que, desde finales del s. XVIII y durante el XIX, promovieron proyectos de riego en diferentes partes de la península. Además, a diferencia de la mayoría de ellas, Híjar culminó con creces la ampliación de la superficie regada. Invirtió más de cinco millones de reales en una obra que, además de Sollana, abastecía nueve términos municipales más. Suministraba agua a partir de contratos privados e individuales con cada propietario. Realizaba las tareas de mantenimiento y pagaba a la dirección del canal las tasas comunes. Constituía, por tanto, una empresa de riego que percibía por el agua un canon proporcional: la veinteava parte de las cosechas (vintena). El peculiar carácter de esta tasa provocaría su asimilación a los pagos de tipo señorial, de manera que, a finales del Setecientos, se extendió la oposición al pago de la vintena, en el contexto de la lucha antiseñorial en la zona. Una sentencia judicial de 1821 confirmó la obligación de pagar el canon por el agua ${ }^{47}$, pese a lo cual los impagos siguieron siendo habituales durante toda la época de la revolución liberal. Sería algunas décadas después cuando los grandes propietarios del segundo tramo del canal firmaron contratos con el duque para convertir la

47 GRAU MANSANET, Ernest, «Nobleza ilustrada y modernización económica en la crisis del Antiguo Régimen», Estudis d'Història Contemporània del País Valencià, 6, 1986, pág. 24. 
vintena en una tasa monetaria. No podemos saber, en el estado actual de la investigación, el balance que esta empresa reportó a las finanzas de la casa de Híjar, pero las pérdidas debieron ser elevadas durante las décadas en que la tasa de riego compartió el destino de les rentas de carácter señorial y del diezmo.

En medio de esta diversidad social que caracterizaba a los integrantes del sistema de riego de la Acequia Real, la intervención de la autoridad política tuvo que ejercer un difícil arbitraje.

\section{CONCLUSIÓN}

La alteración sustancial de la escala y las características del regadío en la Acequia Real del Júcar exigió el cambio y la adecuación de las normas que lo regían desde hacía cinco siglos. El análisis de este proceso ha mostrado la existencia de tres momentos sucesivos. En una primera etapa predominó el conflicto, el deterioro institucional y la pérdida de eficiencia; en un segundo momento, superpuesto en parte al anterior, se produjo la negociación de las nuevas reglas de administración del agua; y en una tercera fase comenzaron a aplicarse estas normas, lo que significaba la trabajosa construcción de un consenso nuevo. En las tres etapas se produjo una intervención de la autoridad política externa al canal, la cual adoptó diferentes grados de intensidad y diferentes objetivos: en la primera de las fases asumió toda la autoridad de la acequia, que estuvo dirigida por diferentes funcionarios dependientes del Estado; después, elaboró un projecto de normas y forzó a las partes enfrentadas a negociarlo; finalmente, facilitó la aplicación de estas normas y arbitró en los conflictos generados en torno a ellas, a través de una intervención menos directa, que restituía gran parte de la autonomía a los regantes pero se reservaba la toma de decisiones en última instancia.

En esta secuencia, la autoridad estatal dirigió el sistema de riego durante periodos prolongados, en la doble faceta de mediador y de gestor. Estas etapas fueron difíciles para el funcionamiento del sistema: el riego perdió eficiencia y el consenso sobre la organización se deterioró. Sin embargo, no es posible atribuir la responsabilidad de todo ello al intervencionismo estatal, como podría sugerir la extensa literatura sobre la gestión estatal de riego en los actuales países en desarrollo. Los problemas en el riego eran, como hemos visto, resultado de los conflictos que el cambio de escala comportaba y se vieron acentuados por el contexto exterior excepcional durante estas décadas de crisis del antiguo régimen. En estas condiciones, la autoridad del Estado, cuestionada por una parte de los regantes e incapaz, a veces, de gestionar el sistema a pleno rendimiento, hizo posible una ampliación del riego de más de 
6.000 hectáreas y la adaptación —en un plazo relativamente corto en la perspectiva secular de esta acequia - de las instituciones colectivas a la nueva configuración del canal.

La intervención estatal, sin embargo, nunca excluyó a los regantes, ya que las normas se negociaron con sus representantes. Los diferentes grupos de usuarios del agua, enfrentados en muchos aspectos, ejercieron en el espacio público tareas de divulgación del modelo organizativo que proponían y trataron de influir en las instituciones que, finalmente, se establecieron. Estas no resultaron extrañas para los regantes locales, ya que incorporaban saberes acumulados por la administración durante las décadas previas de dirección efectiva del canal.

Con todo, la participación de los regantes en esta elaboración de normas estuvo muy restringida a los grandes propietarios de tierras regadas. Estos fueron los que participaron en las reuniones y también aquellos a quienes las nuevas normas capacitaban en exclusiva para ocupar los puestos de gobierno. Ello reflejaba las fuertes desigualdades en la distribución de la tierra y plantea preguntas sobre la formación del consenso en torno a las instituciones de la acequia. No hay acuerdo entre los investigadores sobre si las grandes desigualdades entre regantes facilitan o dificultan la cooperación ${ }^{48}$. Todo depende de los incentivos para actuar a favor de las instituciones colectivas que tengan, en cada caso, los regantes con mayor capacidad de influencia. Por lo que respecta a la Acequia Real, había tres factores que contribuían a la cooperación y a que la supremacía de las élites en los puestos de gobierno no perjudicara los intereses de los pequeños regantes. Por un lado, las grandes propiedades del regadío no estaban concentradas espacialmente sino subdivididas en pequeñas parcelas dispersas y entremezcladas con las tierras del resto de propietarios; estas condiciones hacían muy difícil una gestión del agua que beneficiara a unas partes del territorio en detrimento de otras ${ }^{49}$. En segundo lugar, las desigualdades a escala local se veían contrarrestadas por la existencia de múltiples motivos de conflicto entre los regantes de los diferentes pueblos y con los de otras acequias usuarias del río, de manera que los conflictos horizontales tendían a primar sobre los de carácter vertical ${ }^{50}$. Finalmente, es posi-

48 TANG, S. Y., Institutions and Collective Action, pág. 25; BALAND, Jean-Marie y PlATTEAU, Jean-Philippe, «The Ambiguous Impact of Inequality on Local Resource Management», World Development, 27, 5, 1999, págs. 773-788. BARDHAN, Pranab, «Irrigation and Cooperation: An Empirical Study», en Scarcity, Conflicts, and Cooperation. Essays in the Political and Institutional Economics of Development, Cambridge, Mass., The MIT Press, 2005, pág. 234.

49 GARRIDO, S., «El funcionamiento del regadío», pág. 22.

50 Este es un factor muy destacado en la literatura sobre los efectos de la desigualdad de los regantes sobre la gestión del riego: BARDHAN, Pranab, «Private Property as a Growth Constraint in a Hydraulic Economy», en Land, Labour, and Rural Poverty. Essays in development Economics, Nueva York, Columbia University Press, 1984, págs. 218-219. 
ble que los sectores acomodados tuvieran incentivos no exclusivamente materiales para cooperar: la búsqueda de la distinción, el prestigio y el poder pueden ser factores favorables a la institucionalización de la gestión de los recursos colectivos ${ }^{51}$.

Como en todo proceso de cambio institucional, la nueva reglamentación y la acción política que permitía aplicarla comportaron una redistribución del poder económico de los agentes implicados. En primer lugar, consiguieron integrar a varios miles de nuevos regantes en las estructuras de poder del canal, muy consolidadas por siglos de funcionamiento. Simultáneamente, hicieron posible que el riego en la parte prolongada de la acequia alcanzara los niveles medios de eficiencia del conjunto del canal. Finalmente, integraron dos partes de un mismo canal que tenían un carácter institucional muy diferente: de una parte, un conjunto de comunidades de regantes forjadas en la administración autónoma de la acequia desde la Edad Media; de la otra, un aristócrata propietario de las infraestructuras hidráulicas de la segunda parte del canal, que actuaba como un empresario del agua en relación con los nuevos regantes incorporados.

En definitiva, el proceso de negociación de las nuevas instituciones no desactivó el capital social existente en la gestión final del agua, ya que no afectaban a la reglamentación del riego dentro del ámbito de cada pueblo. Ahí comenzaba otro nivel en la organización del canal, que no hemos explorado en este trabajo y en el cual factores como la reputación, la circulación de información específica y las características sociales locales jugarían un papel determinante. Las tensiones y los conflictos en este nivel también exigieron en ocasiones la intervención de la autoridad política externa, pero, en general, este fue el espacio privilegiado para la autonomía de los regantes.

Recibido: 27-01-2011

Aceptado: 3-11-2011

51 Ostrom, E., Crafting Institutions, págs. 24-25. 